\title{
Perspektif Wisatawan Terhadap Brand Awareness Wisata Halal Sumatera Barat
}

\author{
Mifthah Ghufrani ${ }^{1}$, Niken Febrina Ernungtyas ${ }^{2}$ \\ ${ }^{1,2}$ Program studi Public Relations, STIKOM Inter Studi, \\ Email: miftah.ghufrani1811@gmail.com
}

\begin{abstract}
In the tourism industry, halal tourism is a different concept. Halal tourism is a tour that carries the concept of friendly Muslims for domestic and foreign Muslim tourists. Indonesia with a Muslim majority country has a lot of potential in the halal tourism industry sector. In the procurement of the halal tourism industry, this is implemented according to Islamic law. By providing a place of worship for Muslim tourists, prayer time info, lodging services that provide halal food and drinks, transportation services and other facilities. At present Indonesia has ten provinces with the title of the best halal tourist destination, one of which is the province of West Sumatra. However, the concept of halal tourism is still a lot of people and domestic tourists who do not know it yet. Awareness of halal tourism is also still unknown by the managers of attractions. This study aims to analyze tourist awareness about halal tourism in West Sumatra. In this study using descriptive qualitative methods, with 4 informants interview data collection techniques which are divided into 2 categories, namely, (1) tourists who have visited West Sumatra, and (2) tourists who have never been to West Sumatra. The results showed halal tourism in Indonesia is still classified as a new industrial sector. Travelers know the concept of halal tourism based on the management of tourist attractions that provide places of worship, halal food and beverage restaurants, and other supporting facilitation. And many tourists who are interested in visiting West Sumatra.
\end{abstract}

Keywords: Perspective, Brand Awareness, Halal Tourism 


\section{A. Pendahuluan}

Kegiatan wisata sering dilakukan oleh masyarakat Indonesia di setiap bulan atau tahunnya. Kegiatan tersebut bertujuan untuk menghabiskan waktu luang dan memberikan kepuasan pada diri sendiri. Dalam kegiatan berwisata tersebut, Indonesia memiliki destinasi wisata untuk dikunjungi oleh wisatawan lokal dan mancanegara. Mulai dari wisata panorama alam, wisata rekreasi, dan wisata religi. Di Indonesia wisata religi adalah wisata yang mengandung konteks keagamaan dan sudah ada sejak lama. Jaelani menjelaskan penuturan dari Timotht \& Olsen (2006), Agama memainkan peran penting dalam pengembangan wisata selama berabad-abad dan telah mempengaruhi bagaimana orang memanfaatkan waktu luang ${ }^{1}$.

Banyak wisatawan yang bepergian ke tempat-tempat wisata rohani. Wisata ini mengunjungi tempat-tempat bersejarah yang berkaitan dengan agama yang diyakini, seperti destinasi Masjid Istiqlal, Jakarta; Pura Tanah Lot, Bali; Gereja Blenduk, Semarang; Candi Borobudur dan tempat-tempat destinasi lainnya. Saat ini wisata religi mengalami perkembangan dan perubahan istilah yang kini menjadi wisata halal. Seiring berjalannya waktu, sektor wisata halal sudah banyak berkembang di berbagai negara, salah satunya di Asia Tenggara yaitu Malaysia, berkembangnya wisata halal dikarenakan pertumbuhan penduduk muslim di negara mayoritas.

Berdasarkan data laporan Standing Committee for Economic and Commercial Cooperation of the Organization of Islamic Cooperation (COMCEC), wisatawan muslim yang tersebar di dunia diperkirakan mencapai 116 juta orang ${ }^{2}$. Dalam laporan MasterCard-Crescent Rating Global Muslim Travel Index (GMTI), diperkirakan pada tahun 2020 perjalanan wisatawan muslim akan meningkat sekitar 156 juta perjalanan ${ }^{3}$. Tujuan kegiatan dan penerapan wisata halal seperti yang dijelaskan Kementerian Pariwisata (2019) kegiatan pariwisata didukung oleh fasilitas dan layanan yang disediakan oleh masyarakat, pelaku bisnis, dan pemerintah daerah yang memenuhi aturan ajaran islam.

1 Jaelani, Aan. 2017. Halal Tourism Industry in Indonesia: Potential and Prospects. SSRN Electronic Journal (76237).

${ }^{2}$ Standing Committee for Economic and Commercial Cooperation of the Organization of Islamic Cooperation (COMCEC). 2016. Muslim Friendly Tourism: Understanding the Demand and Supply Sides In the OIC Member Countries. COMCEC Coordination Office (August):1-148.

${ }^{3}$ Mastercard, By. 2018. Global Muslim Travel Index 2018. GMTI (April). 
Dijelaskan oleh Battour berdasarkan data State of the Global Islamic Economy (20142015) terdiri dari 5 aspek yaitu layanan keuangan, makanan halal, busana, media halal dan rekreasi, serta obat-obatan dan kosmetik halal. Indonesia memiliki banyak potensi untuk menyediakan wisata halal yang harus memenuhi beberapa aspek tersebut, seperti ketersediaan makanan halal, fasilitas ibadah yang memadai, fasilitas penginapan dan transportasi ${ }^{4}$. Dalam proses pengembangan industri pariwisata, Kementerian Pariwisata menggelar Kompetisi Pariwisata Halal Tingkat Nasional (KPHN). Ini adalah upaya dari pemerintah untuk mempercepat program wisata halal. Saat ini pemerintah sudah menetapkan provinsi Aceh, Kepulauan Riau, Yogyakarta, Bandung, DKI Jakarta, Lombok, Bali, Sulawesi dan Sumatera Barat sebagai provinsi wisata halal unggulan. Arzil menyebutkan bahwa Dalam ajang KPHN 2016, provinsi Sumatera Barat berhasil meraih dua penghargaan pada kategori; Destinasi Wisata Halal Terbaik dan Destinasi Kuliner Halal Terbaik. Sebagai daerah yang memiliki prinsip budaya "adat basandi syarak, syarak basandi kitabullah" Sumatera Barat berpotensi untuk mengembangkan pasar wisata halal ${ }^{5}$.

Pada tahun 2018 Dinas Pariwisata Provinsi Sumbar menyebutkan sekitar 8,1 juta orang berkunjung ke Sumbar diantaranya terdapat wisatawan mancanegara sebanyak 57.638 orang. Pada tahun 2019 Kementerian Pariwisata telah menetapkan 3 agenda di Sumbar yang masuk dalam kalender pariwisata nasional, yaitu (1) Pasa Harau, (2) Tour de Singkarak, dan (3) Festival Pesona Budaya Minangkabau. Dan pada tahun 2020 Pemprov Sumbar sedang dalam proses penerapan Perda Wisata Halal ${ }^{6}$. Namun dalam menjalankan wisata halal, konsep ini harus dikomunikasikan dengan jelas kepada stakeholders (pemangku kepentingan) dan masyarakat setempat. Salah satunya dengan cara mensosialisasikan agar dapat membangun awareness (kesadaran). Artis menjelaskan pernyataan Kennedy dan Soemanagara (2006) dalam strategi komunikasi bahwa; strategi komunikasi memiliki tiga sasaran perubahan yang terdiri dari

${ }^{4}$ Battour, Mohamed. 2018. Muslim Travel Behavior in Halal Tourism. Mobilities, Tourism and Travel Behavior - Contexts and Boundaries (October 2017).

5 Arzil. 2016. Hegomini Wisata Halal. Telematika. Retrieved https://sumbarprov.go.id/details/news/9214).

${ }^{6}$ Posmetropadang. 2019. 2018, Kunjungan Wisatawan Ke Sumbar 8,1 Juta, 3 Iven Masuk Kalender Pariwisata Nasional - Posmetro Padang. POSMETRO PADANG. Retrieved (https://posmetropadang.co.id/2018-kunjungan-wisatawan-ke-sumbar-81-juta-3-iven-masuk-kalenderpariwisata-nasional/). 
mengubah kesadaran, perhatian, dan kesetiaan. Hal ini menjadi tantangan untuk pemda setempat guna menyampaikan konsep wisata halal pada masyarakat Sumbar. Penelitian ini bertujuan untuk menganalisis wisatawan tentang brand awareness wisata halal di Sumatera Barat. Dengan menganalisis apakah wisatawan aware terhadap konsep wisata halal dan wisatawan berminat berkunjung ke Sumbar untuk berwisata ${ }^{7}$.

\section{B. Tinjauan Pustaka}

\section{Pariwisata Halal}

Indonesia memiliki banyak daerah dan sumber daya alam yang menunjang pertumbuhan pariwisata. Dengan adanya warisan budaya yang berbeda-beda dari segala aspek seperti agama, ras, suku, bahasa, dan adat istiadat menjadi salah satu faktor berkembangnya pariwisata. Jaelani menjelaskan, secara khusus umat Islam sebagai mayoritas masyarakat di Indonesia tentunya memiliki keunikan yang menjadi ciri khas bangsa dengan destinasi pariwisata yang ada, seperti keraton, masjid, benda-benda pusaka, makam, sampai kuliner yang dimilikinya ${ }^{8}$. Destinasi wisata yang mengandung unsur agama, disebut dengan istilah wisata religi. Selama berkembangnya zaman, istilah tersebut mengalami perubahan menjadi wisata syariah yang mengandung prinsip Islam, dan istilah wisata syariah ini mengalami perubahan menjadi wisata halal. Wahidati and Sarinastiti menjelaskan menurut pernyataan Asazuma (2015) mengatakan Wisata halal dapat dikatakan sebagai konsep baru di industri pariwisata yang menawarkan paket dan tujuan wisata yang didesain untuk melayani kebutuhan wisatawan Muslim9 .

Terminologi wisata halal juga merujuk pada banyak istilah diantaranya syariah travel, halal travel, dan muslim friendly. Istilah-istilah tersebut mengacu pada prinsip Islam. Battour and Ismail mendefinisikan bahwa wisata halal adalah objek atau aksi wisata yang memenuhi ketentuan syariat Islam untuk digunakan atau dilibatkan dalam industri pariwisata. Dijelaskan oleh Jaelani menurut penuturan Kementerian Pariwisata (2015) definisi wisata halal lebih luas dari wisata religi yaitu wisata yang didasarkan pada nilai-nilai halal Islam. Seperti yang

\footnotetext{
${ }^{7}$ Artis. 2011. Srategi Komunikasi Public Relations. Jurnal Sosial Budaya 8(02):184-97.

8 Jaelani, Aan. 2017. Halal Tourism Industry in Indonesia: Potential and Prospects. SSRN Electronic Journal (76237).

${ }^{9}$ Wahidati, Lufi and Eska Nia Sarinastiti. 2018. Perkembangan Wisata Halal Di Jepang. Jurnal Gama Societa 1(1):9-19.
} 
dianjurkan oleh World Tourism Organization (WTO), konsumen wisata halal bukan hanya umat Muslim tetapi juga non Muslim yang ingin menikmati kearifan lokal ${ }^{10}$. Penjelasan dari Kementrian Pariwisata tersebut tidak hanya diperuntukan untuk umat muslim saja, tetapi juga bisa dinikmati oleh wisatawan non muslim. Artinya wisatawan non muslim bisa merasakan pengalaman dari berwisata halal tersebut, seperti mendapatkan pelayanan hotel atau penginapan sejenisnya, dengan menyediakan fasilitas terpisah untuk pria dan wanita, seperti kolam renang dan spa, selain itu mendapatkan makanan dan produk-produk yang halal untuk dikonsumsi, serta mendapatkan pelayanan transportasi tanpa menyinggung kaidah dan keyakinan dari agama lain ${ }^{11}$. Dengan banyaknya aspek yang dimiliki oleh sektor wisata halal, akan meningkatkan minat berkunjung dari wisatawan muslim maupun non muslim. Semakin berkembanganya industri parwisata halal, akan semakin banyak minat dari wisatawan yang ingin mengunjungi destinasi tersebut. Namun, dengan diterapkannya konsep wisata halal, harus diiringi dengan sosialisasi pada masyarakat dan wisatawan untuk menumbuhkan kesadaraan (aware). Strategi komunikasi yang tepat untuk mensosialisasikan wisata halal tersebut tidak hanya dengan satu cara komunikasi satu arah, tetapi dari segala arah agar mendapatkan perhatian dan awareness dari wisatawan dan calon wisatawan.

\section{Metode Penelitian}

Metode penelitian ini menggunakan metode kualitatif deskriptif, dan paradigma yang digunakan yaitu interpretif. Menurut Moleong metode deskriptif ini adalah bagian dari karakteristik metode penelitian kualitatif, yang artinya adalah data yang dikumpulkan berupa kata-kata, gambar, dan bukan angka-angka ${ }^{12}$. Penelitian ini bertujuan untuk mendeskripsikan persepsi wisatawan terhadap wisata halal. Dengan menganalisis sudut pandang wisatawan terhadap brand awareness wisata halal Sumbar dan menggali informasi lebih dalam. Dalam penelitian ini ada dua objek yang akan diteliti yaitu;

10 Jaelani, Aan. 2017. Halal Tourism Industry in Indonesia: Potential and Prospects. SSRN Electronic Journal (76237).

${ }^{11}$ Peraturan Menteri Pariwisata. Nomor 29 Tahun 2015. Rencana dan StrategisKementerian Pariwisata Tahun 2015-2019

${ }^{12}$ J.Moleong, Lexy. 2014. Metode Penelitian Kualitatif, Edisi Revisi. Bandung: PT. Rosdakarya. 


\begin{tabular}{|c|c|}
\hline No. & Karakteristik Wisatawan \\
\hline 1 & Wisatawan yang sudah pernah ke Sumbar \\
\hline 2 & Wisatawan yang belum pernah ke Sumbar \\
\hline
\end{tabular}

Tabel 1 : Kategori Penelitian

Untuk subjek penelitian adalah seorang/individu yang pernah melakukan perjalanan wisata ke Sumbar dan seseorang yang belum pernah berwisata ke Sumbar atau sebagai calon wisatawan. Teknik pengumpulan data dengan wawancara mendalam melalui sambungan telepon, whatsapp, dan pesan sebagai data primer. Menurut Moleong jenis wawancara dengan pendekatan ini memakai wawancara yang mengharuskan pewawancara membuat kerangka dan garis besar yang ditanyakan dalam proses wawancara. Dalam penelitian ini Peneliti memilih 4 orang informan secara acak. Peneliti mengajukan sejumlah pertanyaan kepada para informan yang bersedia untuk diwawancarai, membahas topik yang sudah ditentukan.

Wawancara bertujuan untuk menggali informasi mengenai brand awareness terhadap wisata halal Sumbar. Apabila pertanyaan yang diajukan Peneliti masih belum memenuhi data untuk penelitian, maka Peneliti akan mengembangkan pertanyaan lain yang relevan untuk mendapatkan data yang sesuai pada penelitian. Sedangkan untuk data sekunder didapat dari beberapa jurnal, artikel, dan sumber internet. Jika data yang diperlukan sudah cukup dan terkumpul, langkah berikutnya data yang didapatkan dari informan dan sumber terkait akan dikaji oleh Peneliti untuk diolah. Tahap akhir setelah wawancara Peneliti melakukan transkrip wawancara dan menganalisis dengan 3 teknik yaitu, open coding, axial coding, dan selective coding. Proses tersebut untuk pengelompokan data hasil wawancara dengan informan. Data tersebut akan diolah dan menarik kesimpulan dari persepsi wisatawan terhadap brand awareness wisata halal Sumatera Barat.

\section{Hasil dan Pembahasan}

Wisata halal dikategorikan sebagai wisata keagamaan, namun dengan berkembangnya zaman, wisata halal dijadikan konsep disetiap destinasi wisata. Konsep ini berguna untuk semua destinasi wisata, dengan cara memfasilitasi wisatawan dengan adanya tempat ibadah, tempat makan, dan fasilitas penginapan yang berbasis halal. Konsep wisata halal ini juga bisa disebut dengan istilah hospitality, yang berarti destinasi wisata tersebut dapat menjamu wisatawan dengan baik, secara keakraban, ramah tamah dan sopan santun. Dengan istilah tersebut dan 
penerapan yang sesuai akan menimbulkan umpan balik secara tidak langsung dari para wisatawan yang berkunjung. Wisatawan akan merasa dihargai, serta mendapatkan pelayanan dan pengalaman yang menyenangkan, serta kenyamanan saat berkunjung.

Pada penelitian ini, Peneliti mewawancarai 4 orang informan yang sudah dipilih yaitu; D, NS, WN, dan RD.

\begin{tabular}{|c|c|c|c|c|}
\hline $\begin{array}{c}\text { Karakteristik } \\
\text { Informan }\end{array}$ & Informan 1 & Informan 2 & Informan 3 & Informan 4 \\
\hline Nama Informan & Deri (D) & $\begin{array}{c}\text { Novi Safitri } \\
(\mathrm{NS})\end{array}$ & $\begin{array}{c}\text { Wynda Novita } \\
(\mathrm{WN})\end{array}$ & $\begin{array}{c}\text { Rany Desmawati } \\
\text { (RD) }\end{array}$ \\
\hline Domisili & Solok Selatan & Jakarta & Tangerang & Pekanbaru \\
\hline Pekerjaan & Maintenance & Karyawati & Karyawati & Perawat \\
\hline
\end{tabular}

Tabel 2 : Data Informan Penelitian

Peneliti memilih dua informan yang memiliki pengalaman ke Sumbar (wisatawan yang sudah pernah ke Sumbar), dan dua informan terakhir yang belum pernah berkunjung ke Sumbar (wisatawan yang belum pernah ke Sumbar). Informan dengan kategori 'wisatawan yang sudah pernah ke Sumbar' yaitu; D dan RD. “Sudah berapa kali berkunjung ke Sumbar? Dan Destinasi mana saja yang sudah pernah Anda kunjungi di Sumbar?", "Sering karena saya tinggal di Sumbar. Pernah wisata ke Harau, Ngarai Sianok, Lobang Jepang, Jam Gadang, Jenjang Seribu, Puncak Lawang, Istana Pagaruyung, Danau Singkarak, Objek Wisata Minang Fantasi kurang lebih segitu” (informan D, 2 Mei 2020). "Saya dari kecil tinggal di Sumbar tapi saat ini saya kerja di Pekanbaru. Cukup banyak, ke jam gadang, lobang jepang, ngarai sianok, janjang saribu, pantai air manis/malin kundang masjid raya padang, trus ke suliki, harau, kelok 9 ya sejauh ini sudah jalan jalan ke wisata itu” (informan RD, 2 Mei 2020).

Untuk kategori 'wisatawan yang belum pernah ke Sumbar' yaitu informan NS dan WN. Pada pertanyaan wawancara informan NS dan WN mengatakan sudah pernah berwisata dan mengunjungi beberapa kota lain di luar Sumbar. "Kota dan destinasi mana saja dan yang sudah Anda kunjungi untuk berwisata?”, “Jogja, malang, bandung, bogor baru itu saja Oh Iya pernah ke medan juga, sekalian pulkam waktu itu, tapi Aku lupa nama destinasinya apa aja” (informan NS, 1 Mei 2020). “kota bogor, bandung, surabaya, malang, cirebon, palembang. Kebun raya bogor, ke Bandung ke objek wisata yang di Lembang kayak farm house ke malang kota wisata batu kalau nggak salah, kalau ke Cirebon ke tempat makam makam sunan gitu, kalau Palembang pulang kampung” (informan WN, 1 Mei 2020). 
Pada pertanyan berikutnya Peneliti mengajukan pertanyaan tentang wisata halal. "Apakah Anda mengetahui wisata halal?" "Tidak terlalu mengetahuinya tapi pernah dengar". (informan RD, 2 Mei 2020). "Belum, baru ini denger tentang wisata halal" (informan NS, 1 Mei 2020). Berbeda dengan pernyataan informan D dan WN, "tahu tentang wisata halal tapi tidak tahu secara keseluruhan hanya seperti tagline yang saya tahu". (informan D, 2 Mei 2020). "pernah dengar" (informan WN, 1 Mei 2020).

Dua dari empat informan yang diwawancarai, informan RD dan NS menyatakan tidak mengetahui wisata halal. Tidak berbeda dengan dua informan sebelumnya, informan WN pernah mendengar wisata halal. Lalu informan D menyatakan tahu wisata halal namun tidak secara menyeluruh. Pada pertanyaan berikutnya Peneliti mengeksplorasi pertanyaan pada empat informan, tentang konsep wisata halal. "Bagaimana konsep wisata halal menurut Anda?", "Wisata halal ini, bagus karena wisatawan akan tidak perlu khawatir akan makanan yang disajikan di tempat wisata dan tempat ibadah sudah tersedia, kenyamanan dan keamanan sudah terjamin" (informan D, 2 Mei 2020). "Wisata halal itu yang pastinya wisata islami menurut saya, wisata yang lebih ke agama, dan di destinasi tersebut sudah menyediakan fasilitas yang disesuaikan konsep wisata halal" (RD, 2 Mei 2020). "Bagus, keren, menarik dan sangat membantu umat muslim ketika sedang berwisata" (informan NS, 1 Mei 2020). "Bagus, jadi tidak perlu repot repot jika mencari makanan halal juga tempat beribadah" (informan WN, 1 Mei 2020).

Pada pertanyaan konsep wisata halal, informan menyebutkan pendapat menurut pemikiran mereka. Pada pendapat dari informan ini menyatakan wisata halal merupakan konsep yang bagus, keren, menarik, dan wisata yang menerapkan unsur islami. Pertanyaan berikutnya Peneliti mengajukan pertanyaan berbeda pada setiap dua informan. "Menurut Anda, apakah destinasi pariwisata di Sumbar sudah menerapkan konsep wisata halal?", "sudah namun tidak sepenuhnya, karena menurut saya tidak semua orang yang berkunjung adalah wisatawan muslim". (informan D, 2 Mei 2020). "Menurut saya sepertinya sudah tapi belum menyeluruh" (RD, 2 Mei 2020).

Untuk pertanyaan informan berikutnya berbeda dari pertanyaan untuk wisatawan yang sudah pernah ke Sumbar. "Apakah setiap destinasi pariwisata sudah menerapkan konsep wisata halal?", "Belum, terutama di bali. Sepertinya di bali belum menerapkan konsep wisata halal. 
Karna wisatawannya banyak wisatawan asing" (informan NS, 1 Mei 2020). "tidak semua menerapkan wisata halal" (informan WN, 1 Mei 2020)".

\section{Kebijakan Pemda Sumbar menerapkan Wisata Halal}

Pada tahun 2020 pemerintah daerah Sumbar akan merampungkan dan menerapkan perda Wisata Halal untuk wilayah Sumbar. Pada pertanyaan selanjutnya Peneliti menganalisis jawaban setuju atau tidak setuju dari jawaban informan. "Apakah Anda Setuju/Tidak Setuju dengan penerapan konsep wisata halal di setiap destinasi di Sumbar?", “Setuju. Pertama mayoritas penduduk Sumbar Muslim, konsep wisata halal berbasis syariah, dan pasti aman dan terfasilitasi untuk wisatawan muslim dan non muslim. Sudah ada sarana ibadah, makanan yang halal, dan toilet yg memenuhi standar" (informan D, 2 Mei 2020).

"setuju agar lebih mudah wisatawan dapat fasilitas ibadah, tempat makan yang halal, dan dapat kenyamanan" (informan RD, 2 Mei 2020).

"sangat setuju, karena indonesia merupakan negara dengan mayoritas muslim sehingga penerapan wisata halal sangat tepat diterapkan di setiap destinasi wisata" (informa WN. 1 Mei 2020).

Namun pada pertanyaan tersebut, Peneliti mendapatkan jawaban berbeda dari informan NS yang tidak setuju dengan kebijakan pemerintah, "Tidak setuju, karena indonesia itu bhineka tunggal ika. Suku, budaya dan agamanya beragam. Jadi belum bisa jika dibuat konsep halal, karena penduduk indonesia tidak hanya umat muslim saja. Masih banyak agama yg lain” (informan NS, 1 Mei 2020). Tujuan dari penerapan perda Wisata Halal untuk mengukuhkan sejumlah destinasi yang di Sumbar dan menetapkan Sumbar sebagai provinsi destinasi wisata halal di Indonesia. Namun pada pertanyaan tersebut menurut informan NS yang tidak setuju karena Indonesia memiliki suku, ras, dan agama yang berbeda-beda. Akan tetapi tiga informan $\mathrm{D}$, RD, dan WN menyetujui kebijakan tersebut dan berpendapat dengan adanya penerapan kebijakan tersebut, akan memudahkan setiap wisatawan beribadah, mencari makanan halal, serta mendapatkan fasilitas yang baik dari konsep wisata halal tersebut.

Umumnya wisata biasa berbeda dengan wisata halal, selanjutnya Peneliti mengajukan pertanyaan tentang perbedaan wisata halal dan wisata biasa. "Menurut Anda; apa yang menjadi perbedaan wisata halal dengan wisata biasa pada umumnya?", "yang pertama fasilitas untuk 
wisata halal sudah tercukupi seperti tempat sholat, istirahat, dan tempat ibu yang memiliki bayi, sementara wisata biasa pada umumnya tidak semua fasilitasnya terpenuhi. Itu memang tempat wisata tapi tidak memiliki fasilitas yang memadai”(informan D, 2 Mei 2020).

"Kalau wisata umum atau yang biasa, di Sumbar banyak yang tidak ada fasilitas yang memadai seperti rumah makan tidak ada, hanya warung warung kecil saja, mushola tidak ada. Tapi kalau wisata halal pasti sudah ada fasilitas ibadah, rumah makan yang halal trus hotelnya juga berbasis islami” (informan RD, 2 Mei 2020).

"Perbedaan paling utamanya dari konsep yg dibuat. Wisata halal membuat konsep dengan unsur agama yg lebih kuat. Kalau wisata umumnya membuat konsep biasa sesuai dengan norma dan aturan saja” (informan NS, 1 Mei 2020).

"perbedaannya pada makanan juga tempat tujuan beribadah, sehingga dalam berwisata memudahkan wisatawan untuk menemukan makanan halal juga tempat ibadah" (informan WN, 1 Mei 2020).

Pada pertanyaan ini rata-rata informan menyebutkan perbedaan terletak pada fasilitas ibadah dan tempat makanan yang halal. Lalu pada pertanyaan selanjutnya Peneliti menanyakan "Menurut Anda; apakah Sumbar sudah bisa dinyatakan sebagai destinasi wisata halal di Indonesia?", "Sudah, karena mayoritas destinasi sudah memiliki kategori pariwisata halal" (informan D, 2 Mei 2020).

"Menurut saya sudah bisa dikatakan sebagai destinasi wisata halal, karena budaya yang mengandung nilai agama islam, masyarakat minang yang rata rata beragama islam, dan pasti bisa menjadikan tempat wisata tersebut menjadi wisata halal" (informan RD, 2 Mei 2020).

"Menurut saya sepertinya sudah karna wilayah Sumbar sangat islami, itu pendapat saya walaupun belum pernah kesana” (informan NS, 1 Mei 2020).

"Bisa karena Sumbar mayoritas penduduk muslim dan mereka mengelolanya juga mengikuti aturan agama islam” (informan WN, 1 Mei 2020).

Jawaban dari keempat informan menyatakan, bahwa Sumbar layak dinyatakan sebagai destinasi halal di Indonesia. Karena dari mayoritas orang minang beragama islam, budaya dengan agama islam yang kuat, dan dapat mengelola sumber daya dari wilayah tersebut menjadi wisata halal. 


\section{Minat Berwisata ke Sumbar}

Setiap wisatawan pasti memiliki minat dan keinginan berkunjung ke destinasi dan kota yang belum pernah dikunjungi. Pertanyaan terakhir pada penelitian ini, Peneliti menanyakan minat dan keinginan informan berwisata ke Sumbar. "Rencana saya akan berkunjung ke Mentawai karena belum semua wilayah dijelajahi” (informan D, 2 Mei 2020).

"Pastinya saat saya pulang ke kampung nanti, akan jalan jalan ke tempat yang belum saya kunjungi seperti di Painan, di Mentawai dan lainnya” (informan RD, 2 Mei 2020).

"Berminat sekaliiiii, ingin mengunjungi jam gadang, lembah harau, pantai padang, kelok sembilan” (informan NS, 1 Mei 2020).

"berminat, destinasinya berada di daerah bernama padang disana ada tempat wisata seperti pantai padang, pantai carolina serta jembatan siti nurbaya” (informan WN, 1 Mei 2020).

\begin{tabular}{|c|c|c|c|c|}
\hline & $\begin{array}{c}\text { Informan } 1 \\
\text { (D) }\end{array}$ & $\begin{array}{c}\text { Informan } 2 \\
\text { (NS) }\end{array}$ & $\begin{array}{c}\text { Informan } 3 \\
(W N)\end{array}$ & $\begin{array}{c}\text { Informan } 4 \\
\text { (RD) }\end{array}$ \\
\hline $\begin{array}{c}\text { Wisatawan } \\
\text { mengetahui } \\
\text { konsep Wisata } \\
\text { Halal }\end{array}$ & $\begin{array}{c}\text { Mengetahui } \\
\text { konsep wisata } \\
\text { halal }\end{array}$ & $\begin{array}{c}\text { Belum } \\
\text { mengetahui } \\
\text { konsep wisata } \\
\text { halal }\end{array}$ & Pernah dengar & $\begin{array}{l}\text { Tidak terlalu } \\
\text { mengetahui, } \\
\text { tetapi pernah } \\
\text { mendengar } \\
\text { konsep wisata } \\
\text { halal }\end{array}$ \\
\hline $\begin{array}{c}\text { Wisatawan } \\
\text { mengetahui } \\
\text { perbedaan } \\
\text { wisata halal } \\
\text { dan wisata } \\
\text { umum }\end{array}$ & $\begin{array}{c}\text { pertama } \\
\text { fasilitas untuk } \\
\text { wisata halal } \\
\text { sudah tercukupi } \\
\text { seperti tempat } \\
\text { sholat, istirahat, } \\
\text { dan tempat ibu } \\
\text { yang memiliki } \\
\text { bayi, sementara } \\
\text { wisata umum } \\
\text { tidak semua } \\
\text { fasilitasnya } \\
\text { terpenuhi. Itu } \\
\text { memang } \\
\text { tempat wisata } \\
\text { tapi tidak } \\
\text { memiliki } \\
\text { fasilitas yang } \\
\text { memadai }\end{array}$ & $\begin{array}{c}\text { Perbedaan } \\
\text { paling } \\
\text { utamanya dari } \\
\text { konsep yg } \\
\text { dibuat. Wisata } \\
\text { halal membuat } \\
\text { konsep dengan } \\
\text { unsur agama yg } \\
\text { lebih kuat. } \\
\text { Kalau wisata } \\
\text { umumnya } \\
\text { membuat } \\
\text { konsep biasa } \\
\text { sesuai dengan } \\
\text { norma dan } \\
\text { aturan saja }\end{array}$ & $\begin{array}{c}\text { perbedaannya } \\
\text { pada makanan } \\
\text { juga tempat } \\
\text { tujuan } \\
\text { beribadah, } \\
\text { sehingga dalam } \\
\text { berwisata } \\
\text { memudahkan } \\
\text { wisatawan } \\
\text { untuk } \\
\text { menemukan } \\
\text { makanan halal } \\
\text { juga tempat } \\
\text { ibadah }\end{array}$ & $\begin{array}{c}\text { wisata umum } \\
\text { atau yang biasa, } \\
\text { di Sumbar } \\
\text { banyak yang } \\
\text { tidak ada } \\
\text { fasilitas yang } \\
\text { memadai } \\
\text { seperti rumah } \\
\text { makan tidak } \\
\text { ada, hanya } \\
\text { warung warung } \\
\text { kecil saja, } \\
\text { mushola tidak } \\
\text { ada. Tapi kalau } \\
\text { wisata halal } \\
\text { pasti sudah ada } \\
\text { fasilitas ibadah, } \\
\text { rumah makan } \\
\text { yang halal trus } \\
\text { hotelnya juga } \\
\text { berbasis islami }\end{array}$ \\
\hline
\end{tabular}




\begin{tabular}{|c|c|c|c|c|}
\hline $\begin{array}{c}\text { Wisata Halal } \\
\text { menurut } \\
\text { wisatawan }\end{array}$ & $\begin{array}{c}\text { Wisata halal } \\
\text { ini, bagus } \\
\text { karena } \\
\text { wisatawan } \\
\text { tidak perlu } \\
\text { khawatir akan } \\
\text { makanan yang } \\
\text { disajikan di } \\
\text { tempat wisata } \\
\text { dan tempat } \\
\text { ibadah sudah } \\
\text { tersedia, } \\
\text { kenyamanan } \\
\text { dan keamanan } \\
\text { sudah terjamin }\end{array}$ & $\begin{array}{c}\text { Bagus, keren, } \\
\text { menarik dan } \\
\text { sangat } \\
\text { membantu } \\
\text { umat muslim } \\
\text { ketika sedang } \\
\text { berwisata }\end{array}$ & $\begin{array}{l}\text { Bagus, jadi } \\
\text { tidak perlu } \\
\text { repot repot jika } \\
\text { mencari } \\
\text { makanan halal } \\
\text { juga tempat } \\
\text { beribadah }\end{array}$ & $\begin{array}{l}\text { Wisata halal itu } \\
\text { yang pastinya } \\
\text { wisata islami } \\
\text { menurut saya, } \\
\text { wisata yang } \\
\text { lebih ke agama, } \\
\text { dan di destinasi } \\
\text { tersebut sudah } \\
\text { menyediakan } \\
\text { fasilitas yang } \\
\text { disesuaikan } \\
\text { konsep wisata } \\
\text { halal }\end{array}$ \\
\hline $\begin{array}{c}\text { Wisatawan } \\
\text { tentang } \\
\text { kebijakan } \\
\text { pemerintah } \\
\text { menerapkan } \\
\text { Wisata Halal }\end{array}$ & $\begin{array}{c}\text { Setuju. Pertama } \\
\text { mayoritas } \\
\text { penduduk } \\
\text { Sumbar } \\
\text { Muslim, } \\
\text { konsep wisata } \\
\text { halal berbasis } \\
\text { syariah, dan } \\
\text { pasti aman dan } \\
\text { terfasilitasi } \\
\text { untuk } \\
\text { wisatawan } \\
\text { muslim dan } \\
\text { non muslim. } \\
\text { Sudah ada } \\
\text { sarana ibadah, } \\
\text { makanan yang } \\
\text { halal, dan toilet } \\
\text { yg memenuhi } \\
\text { standar }\end{array}$ & $\begin{array}{c}\text { Tidak setuju, } \\
\text { karena } \\
\text { indonesia itu } \\
\text { bhineka } \\
\text { tunggal ika. } \\
\text { Suku, budaya } \\
\text { dan agamanya } \\
\text { beragam. Jadi } \\
\text { belum bisa jika } \\
\text { dibuat konsep } \\
\text { halal, karena } \\
\text { penduduk } \\
\text { indonesia tidak } \\
\text { hanya umat } \\
\text { muslim saja. } \\
\text { Masih banyak } \\
\text { agama yg lain }\end{array}$ & $\begin{array}{c}\text { sangat setuju } \\
\text { karena } \\
\text { indonesia } \\
\text { merupakan } \\
\text { negara dengan } \\
\text { mayoritas } \\
\text { muslim } \\
\text { sehingga } \\
\text { penerapan } \\
\text { wisata halal } \\
\text { sangat tepat } \\
\text { diterapkan di } \\
\text { setiap destinasi } \\
\text { wisata }\end{array}$ & $\begin{array}{c}\text { setuju agar } \\
\text { lebih mudah } \\
\text { wisatawan } \\
\text { dapat fasilitas } \\
\text { ibadah, tempat } \\
\text { makan yang } \\
\text { halal, dan dapat } \\
\text { kenyamanan }\end{array}$ \\
\hline $\begin{array}{c}\text { Wisatawan } \\
\text { Yang dapat } \\
\text { menikmati } \\
\text { wisata halal }\end{array}$ & $\begin{array}{l}\text { semua orang } \\
\text { baik muslim } \\
\text { atau non } \\
\text { muslim selama } \\
\text { mengikuti rules } \\
\text { yang berlaku }\end{array}$ & $\begin{array}{c}\text { Semua orang } \\
\text { bisa menikmati } \\
\text { wisata halal, } \\
\text { selama masih } \\
\text { bisa mengikuti } \\
\text { aturan dan } \\
\text { konsep yg } \\
\text { dibuat oleh } \\
\text { wisata halal }\end{array}$ & $\begin{array}{l}\text { wisatawan } \\
\text { muslim juga } \\
\text { non muslim }\end{array}$ & $\begin{array}{c}\text { Semua orang } \\
\text { bisa menikmati, } \\
\text { turis luar negeri } \\
\text { juga bisa } \\
\text { menikmatinya }\end{array}$ \\
\hline
\end{tabular}




\begin{tabular}{|c|c|c|c|c|}
\hline $\begin{array}{c}\text { Pendapat } \\
\text { informan } \\
\text { terhadap } \\
\text { wisatawan non } \\
\text { muslim } \\
\text { berwisata } \\
\text { halal }\end{array}$ & $\begin{array}{c}\text { Menurut saya } \\
\text { tentunya tidak } \\
\text { merasa } \\
\text { terganggu, } \\
\text { karena } \\
\text { wisatawan } \\
\text { yang akan } \\
\text { datang } \\
\text { berkunjung } \\
\text { pasti sudah } \\
\text { mengerti dan } \\
\text { memahami } \\
\text { peraturan yang } \\
\text { ada pada } \\
\text { destinasi } \\
\text { tersebut }\end{array}$ & $\begin{array}{c}\text { Menurut saya } \\
\text { masyarakat } \\
\text { indonesia } \\
\text { menjunjung } \\
\text { tinggi toleransi } \\
\text { dan } \\
\text { kebhinekaan. } \\
\text { Jadi tidak } \\
\text { merasa } \\
\text { terganggu, } \\
\text { karena saling } \\
\text { menghargai } \\
\text { dan } \\
\text { menghormati } \\
\text { satu sama lain } \\
\text { walau berbeda } \\
\text { keyakinan }\end{array}$ & $\begin{array}{c}\text { tidak juga. } \\
\text { wisatawan non } \\
\text { muslim harus } \\
\text { menaati } \\
\text { peraturan } \\
\text { pariwisata di } \\
\text { daerah dimana } \\
\text { mereka } \\
\text { berwisata }\end{array}$ & $\begin{array}{c}\text { Seharusnya } \\
\text { tidak, karena } \\
\text { wisatawan non } \\
\text { muslim seperti } \\
\text { wisatawan } \\
\text { asing bisa } \\
\text { mengikuti } \\
\text { peraturan dan } \\
\text { menikmati } \\
\text { layanan yang } \\
\text { ada di wisata } \\
\text { halal tersebut }\end{array}$ \\
\hline $\begin{array}{c}\text { Pendapat } \\
\text { wisatawan } \\
\text { Wisata Halal } \\
\text { layak di } \\
\text { Sumbar }\end{array}$ & $\begin{array}{l}\text { Sudah, karena } \\
\text { mayoritas } \\
\text { destinasi sudah } \\
\text { memiliki } \\
\text { kategori } \\
\text { pariwisata halal }\end{array}$ & $\begin{array}{l}\text { Menurut saya } \\
\text { sepertinya } \\
\text { sudah karna } \\
\text { wilayah } \\
\text { Sumbar sangat } \\
\text { islami, itu } \\
\text { pendapat saya } \\
\text { walaupun } \\
\text { belum pernah } \\
\text { kesana }\end{array}$ & $\begin{array}{c}\text { Bisa karena } \\
\text { Sumbar } \\
\text { mayoritas } \\
\text { penduduk } \\
\text { muslim dan } \\
\text { mereka } \\
\text { mengelolanya } \\
\text { juga mengikuti } \\
\text { aturan agama } \\
\text { islam }\end{array}$ & $\begin{array}{c}\text { Menurut saya } \\
\text { sudah bisa } \\
\text { dikatakan } \\
\text { sebagai } \\
\text { destinasi wisata } \\
\text { halal, karena } \\
\text { budaya yang } \\
\text { mengandung } \\
\text { nilai agama } \\
\text { islam, } \\
\text { masyarakat } \\
\text { minang yang } \\
\text { rata rata } \\
\text { beragama } \\
\text { islam, dan pasti } \\
\text { bisa } \\
\text { menjadikan } \\
\text { tempat wisata } \\
\text { tersebut } \\
\text { menjadi wisata } \\
\text { halal }\end{array}$ \\
\hline $\begin{array}{c}\text { Wisatawan } \\
\text { berminat } \\
\text { wisata ke } \\
\text { Sumbar }\end{array}$ & $\begin{array}{c}\text { Rencana saya } \\
\text { akan } \\
\text { berkunjung ke } \\
\text { Mentawai } \\
\text { karena belum } \\
\text { semua wilayah } \\
\text { dijelajahi } \\
\end{array}$ & $\begin{array}{c}\text { Berminat } \\
\text { sekali, ingin } \\
\text { mengunjungi } \\
\text { jam gadang, } \\
\text { lembah harau, } \\
\text { pantai padang, } \\
\text { kelok sembilan }\end{array}$ & $\begin{array}{c}\text { berminat, } \\
\text { destinasinya } \\
\text { berada di } \\
\text { daerah bernama } \\
\text { padang disana } \\
\text { ada tempat } \\
\text { wisata seperti }\end{array}$ & $\begin{array}{c}\text { Pastinya saat } \\
\text { saya pulang ke } \\
\text { kampung nanti, } \\
\text { akan jalan jalan } \\
\text { ke tempat yang } \\
\text { belum saya } \\
\text { kunjungi }\end{array}$ \\
\hline
\end{tabular}




\begin{tabular}{|l|l|c|c|}
\hline & & $\begin{array}{c}\text { pantai padang, } \\
\text { pantai carolina } \\
\text { serta jembatan } \\
\text { siti nurbaya }\end{array}$ & $\begin{array}{c}\text { seperti di } \\
\text { Painan, di } \\
\text { Mentawai dan } \\
\text { lainnya }\end{array}$ \\
\hline
\end{tabular}

Tabel 3 : Ringkasan Penelitian

\section{E. Simpulan}

Hasil penelitian mendeskripsikan perspektif wisatawan terhadap brand awareness wisata halal. Menurut para wisatawan, mereka mengetahui konsep wisata halal. Namun, wisata halal ini masih tergolong baru di Indonesia karena penerapan yang masih belum menyeluruh. Mereka juga mengetahui perbedaan wisata halal dengan wisata biasa pada umumnya.

Menurut wisatawan konsep wisata halal ini bagus dan keren. Karena konsep ini pastinya sudah menyediakan fasilitas standar wisata halal seperti tempat ibadah, makanan dan minuman yang halal, dan fasilitas lainnya seperti penginapan atau transportasi yang menerapkan syariat islam.

Program wisata halal di Sumbar kini sudah diterapkan oleh pemerintah. Menurut wisatawan, mereka setuju dengan kebijakan tersebut. Karena mayoritas penduduk Indonesia terutama di Sumbar adalah umat muslim, dan Sumbar juga memiliki potensi pariwisata halal. Provinsi Sumbar juga berhasil meraih dua penghargaan pada kategori; Destinasi Wisata Halal Terbaik dan Destinasi Kuliner Halal Terbaik pada ajang KPHN 2016. Dan Sumbar layak menjadi provinsi destinasi wisata halal.

Pada konsep ini, tidak hanya wisatawan muslim saja yang dapat merasakan dan menikmati wisata halal. Menurut wisatawan, wisatawan non muslim juga dapat menikmati konsep wisata halal tanpa merasa terganggu, dapat mengikuti peraturan yang sudah diterapkan di setiap area pariwisata. Dengan begitu mereka dapat merasakan pengalaman berbeda dan tetap menghargai antar umat beragama. Para wisatawan pun juga memiliki minat untuk berwisata ke Sumbar. Menurut wisatawan, mereka cukup banyak mengetahui destinasi pariwisata yang terkenal di Sumbar.

\section{Daftar Pustaka}

Adinugraha, Hendri Hermawan, Mila Sartika, and Ana Kadarningsih. 2018. Desa Wisata Halal : Konsep Dan Implementasinya Di Indonesia. Human Falah 5(1):28-48.

Artis. 2011. Srategi Komunikasi Public Relations. Jurnal Sosial Budaya 8(02):184-97. 
Arzil. 2016. Hegomini Wisata Halal. Telematika. Retrieved (https://sumbarprov.go.id/details/news/9214).

Battour, Mohamed. 2018. Muslim Travel Behavior in Halal Tourism. Mobilities, Tourism and Travel Behavior - Contexts and Boundaries (October 2017).

Battour, Mohamed and Mohd Nazari Ismail. 2016. Halal Tourism: Concepts, Practises, Challenges and Future. Tourism Management Perspectives 19(May 2020):150-54.

J. Moleong, Lexy. 2014. Metode Penelitian Kualitatif, Edisi Revisi. Bandung: PT. Rosdakarya.

Jaelani, Aan. 2017. Halal Tourism Industry in Indonesia: Potential and Prospects. SSRN Electronic Journal (76237).

Mastercard, By. 2018. Global Muslim Travel Index 2018. GMTI (April).

Murdana, I. Made Murdana. 2019. Pendekatan Unique Point Selling (Ups) Dlm Reformulasi Strategi Pemasaran Pulau Gili Trawangan Pasca Gempa. Ganec Swara 13(1):181.

Peraturan Menteri Pariwisata. Nomor 29 Tahun 2015. Rencana dan StrategisKementerian Pariwisata Tahun 2015-2019.

Posmetropadang. 2019. 2018, Kunjungan Wisatawan Ke Sumbar 8,1 Juta, 3 Iven Masuk Kalender Pariwisata Nasional - Posmetro Padang. POSMETRO PADANG. Retrieved (https://posmetropadang.co.id/2018-kunjungan-wisatawan-ke-sumbar-81-juta-3-ivenmasuk-kalender-pariwisata-nasional/).

Pratiwi, Soraya Ratna, Susanne Dida, and Nuryah Asri Sjafirah. 2018. Strategi Komunikasi Dalam Membangun Awareness Wisata Halal Di Kota Bandung. Jurnal Kajian Komunikasi $6(1): 78$.

Standing Committee for Economic and Commercial Cooperation of the Organization of Islamic Cooperation (COMCEC). 2016. Muslim Friendly Tourism: Understanding the Demand and Supply Sides In the OIC Member Countries. COMCEC Coordination Office (August):1148.

Wahidati, Lufi and Eska Nia Sarinastiti. 2018. Perkembangan Wisata Halal Di Jepang. Jurnal Gama Societa 1(1):9-19. 